\title{
Identification and determination of the relations of Components of Information Technology in Supply Chain Management with Fuzzy DEMATEL method (Case study: Pars Khodro Company)
}

\author{
Gholamreza Jandaghi, Seyed Mohammadbagher Jafari, Pouria Salimi \\ Faculty of Management and Accountin, Farabi College, University of Tehran, Iran \\ E-mail address: jandaghi@ut.ac.ir, Sm.jafari@ut.ac.ir \\ pouriasalimi616@gmail.com
}

\begin{abstract}
Keywords: supply chain management, information technology, fuzzy set theory, DEMATEL method
\end{abstract}

\begin{abstract}
In the business environment, information technology plays an important role in of firms' performance. information technology provides information flow which makes the supply chain more robust and resilient. There are plenty of researches about the role of SCM in companies, but few researches has been done the investment of IT in SCM and what extend it for to provide advantage in automotive companies. This study attempts to identify and determine of relations of components of information technology in supply chain management. Thus, the components identified according to review of literature with library study and by means of experts questionnaire was conducted toward validity, reliability, and selection of components. Eventually, seven components were selected for information technology in supply chain management. The Fuzzy DEMATEL method was applied to determine the interrelationships amongst all components. The results showed that were identified the component of Customer Relationship Management (CRM) as the most important component, and the other hand, Advanced Planning Systems (APS) as the most effective component.
\end{abstract}

\section{INTRODUCTION}

Companies must have access to a different information about suppliers, customers, and their productions and services for to perform their affairs. They must organize the activities that this information to use for improvement the overall performance of their company, information systems is made possible for companies until manage all of their information, and make a better decision and improve the implementation of processes of their business. Use of information technology systems for taking and analyze data can be have a great positive effects on better performance of firms. Lack of access to information technology has adverse effects on achieving the competitive priority on environment dynamics, and also companies can't give an appropriate response to market changes, and will increase production costs and so that gradually lost competitiveness in their industry (M.L.Tseng, K.J.Wu and T.Nguyen, 2011).

In the other hand, increasing competitiveness and effort for the survival of companies that has been made with approach to the communication and advance in information technology is created a situation for supply chain management. Organizations knows secret of their survival in satisfy the needs of their customers. These needs can being includes, price reduce, in time transportation, suitable quality and etc, that supply chain management is an attitude that leads to supply these needs. Supply chain management is one of the new scientific issues that the attention of many experts and researchers has attracted and in today's business environment the growing important of supply chain has been caused that companies in around the world accept their supply chain management as an very important element and necessity for their survival ( Stadtler and Hartmut, 2000). 
There are plenty researches about the role of supply chain management in companies, but few researches has been done about the investment of IT in SCM, and to what extend it providing benefit in automotive companies. In today's business environment information technology plays an important role for firms' performance. Information technology provides an information flow which makes the supply chain more robust and resilient. With the increasing use of an integrated information systems and enabling technologies, the supply chain can build which to eliminate poor performance of suppliers, unpredictable customer demands, and uncertain business environment.

As a result of this issue this study attempts to Identification and Determination relationships of components of information technology in supply chain management.

In a review of research literature, in a research was conducted with title of information technology in supply chain management attempts to prove the impact of information technology in supply chain management. The results finds that advanced IT is the cause criteria leading to marketing performance and customer satisfaction (M.L.Tseng, K.J.Wu and T.Nguyen, 2011). In another research with title of Information Systems in supply chain integration and management, the literature available on IT in SCM have been classified and then develop a framework for studying the applications of IT in SCM. Based on this review and analysis, recommendations have been made regarding the application of IT in SCM (A.Gunasekaran,E.W.T.Ngai , 2004). In a research with title of the impact of Information Technology on the development of Supply Chain Competitive Advantage, explores the impact of information technology practices on building competitive advantage throughout the supply chain. The empirical findings from a survey of 76 manufacturing firms in Greece confirmed companies must exploit IT including enterprise applications such as ERP and CRM, as well as e-procurement and e-commerce, and the crucial role of IT practices and techniques on the establishment of a sustainable competitive advantage based on Supply Chain Management (C.Marinagi, P.Terivellas, D. P. Sakas, 2014). In a research with title of the effects of process development and information technology on time-based supply chain performance, purpose of the study is to reveal the individual and cumulative effects of information technology and process development activities on time-based supply chain performance which is a key strategic component of the business competitiveness. According to findings of the research firms mostly consider the importance of information sharing by IT, while using intranet applications takes second place. These finding still don't operate in a SC integrated by IT applications, or don't recognize the value to operate in SC (A.Z.Acar, N.B.Uzunlar, 2014).

By examining conducted studies on the subject of current study which is identification and determination relationships of components of information technology in supply chain management, there are many researches about the role of SCM in companies, but few research has been done about the investment of IT in SCM, and to what extend it providing benefit in automotive companies.

Therefore, in this current study first, with the study of these investigations, and related books with the research topic, components were identified for information technology in supply chain management, and with by means of the expert questionnaire was conducted toward validity, reliability, and selection of components. Eventually, seven components were selected for information technology in supply chain management. The Fuzzy DEMATEL method was applied to determine the relationships amongst all components.

\section{INFORMATION TECHNOLOGY IN SUPPLY CHAIN MANAGEMENT}

Recent studies show that information technology as a basic platform are considered to integrate all activities of supply chain from raw material preparation up to the delivery of the goods to the final consumers. Supply chain management must to integrate all of chain internal systems such as inventory management, elimination the time and place limitations, access to the world markets, reducing time and cost of operations, making flat chain structure, increasing flexibility of chain, quality assurance, production planning, storage, transportation and also chain external systems such as customer relationship management systems and supplier relationship management through implementation of the information technology. 
This integrating system of supply chain management collects all information from around the supply chain and puts in the hands of managers in the form of managerial reports, until these managers with wide and comprehensive vision make strategic decisions for the entire of chain at the right time. Also, this system have saving time and cost in across the chain by integrating processes and data. Benefits of these systems including on time access to right information, facilitate processes, and elimination operational constraints in the supply chain (Chopra, Mendel, 2003).

In this research, first by means of research literature review components considered for information technology in supply chain management, than by means of expert opinions was conducted toward validity and reliability of components, eventually the following components are considered for information technology in supply chain management.

Material requirements planning (MRP) (C1) is an appropriate tool for detailed planning of material supply in the manufacturing and assembly of parts into finished products. The aim of this system is to provide the right parts in the right place and time in order to be conducted on time production and delivery. To achieve this aim MRP provides a formal and specific program for every part of production, raw material, semi-finished parts and final production (Koh, 2004). Enterprise resource planning (ERP) (C2), enterprise resource planning systems are a software packages that allows to organizations to integrate their components and having more control on their activities. Manufacturing organizations have been main groups of users of this software. In among of these organizations automotive companies because of having numerous processes and significant financial potential have the largest share in the implementation of these softwares. ERP systems are very complex and integrated systems that thousands of organizations in the world need it for success in their business (Koch, 1996). Advanced planning system (APS) (C3) is a kind of production management process that within resources and production capacities are allocated optimally. In fact, advanced planning systems are systems that plan the real production based on volume of forecasts and actual orders. This approach used in the environments that simple planning can't respond to complex conditions (Chen, Lin, 2008). Supplier relationship management (SRM) (C4) supplier relationship management systems can have a benefits for the both sides (seller and buyer). Buyers obtains a reliable resources of goods that need with reasonable prices and reliable results. Also they do not have to for buying the products be looking for sellers repeatedly, and also sellers obtains stable resource of trade and benefit. Further collaboration between suppliers and buyers can create more benefits such as constant monitoring of inventories and real and on time information (Kaske, 2002). Customer relationship management (CRM) (C5) customer relationship management systems help to companies in order to manage the communications with customers. These systems provides Required information for the harmonization of all the processes of business related to customers in the field of sale and marketing and required service to optimize of revenue, customer satisfying, and keeping of customers. These information help to companies in order to profitable customer identified, attracted, and keep, better services give to customers, and finally, increase their sale (Laudon, 2006). RFID, GPS, mobile and wireless (C6) coordination of the different units is a very complex and difficult act in supply chain. Information technology was identified as a solution for this problem through the information sharing, automating processes, and integration of supply chain management. The advances in information technology, internet security improvement, and bandwidth has caused spreading use of mobile and wireless technologies. These technologies have many advantages for organizations for example GPS technology is used in order to providing service to customers in the moment. Applications and softwares of information technology enables the organizations until be connected to the central computer by means of GPS, GIS, Wimax, and Wi Fi technologies and allows the users to share their information throughout the supply chain. For example RFID technology along with a short message service and mobile portals allows to users access to on time information in throughout the supply chain (Eng, 2005). Data electronic interchange (DEI) (C7) this technology are used to automate the office interchanges such as sending and receiving of orders, invoices, sheets transport and delayed of orders. Members of supply chain can share the demand data at creation time by means of DEI, and have the prediction 
of demand. This affair can reduce the unclear that is increasing in upstream loops of supply chain (Bort and Bielfeldt, 1994).

Table1.Proposed components

\begin{tabular}{|c|c|}
\hline The symbol & $\begin{array}{c}\text { Components of Information Technology in Supply } \\
\text { Chain Management }\end{array}$ \\
\hline C1 & Material Requirement Planning (MRP) \\
\hline C2 & Enterprise Resource Planning (ERP) \\
\hline C3 & Advanced Planning Systems (APS) \\
\hline C4 & Supplier Relationship Management (SRM) \\
\hline C5 & Customer Relationship Management (CRM) \\
\hline C6 & RFID, GPS, mobile and wireless \\
\hline C7 & Data Electronic Interchange (DEI) \\
\hline
\end{tabular}

\section{DEMATEL Method}

Decision Making Trail and Evaluation Laboratory (DEMATEL) method was first conceived by the battelle memorial institute through its research in the Geneva Research Centre in 1973. DEMATEL method is used to analyze the relations among different criteria. The DEMATEL method based on diagraphs. A diagraph or directional graph classifies factors into cause and effect groups. It depicts a relation between these groups. DEMATEL converts this relationship into an effective structural model (Baruahe.S, Raj.S, Ray.A, Chacravorty.S, 2012).

\section{Fuzzy set theory}

Fuzzy theory was released by Lotfi zadeh professor, Iranian scientist and professor of the Berkeley campus America. This theory of the releasing time so far has earned expanding and a great deepen, and various uses has found in different fields. fuzzy theory, a theory is for action in uncertain situation. This theory is able to transform many concepts, variables, and ambiguous and unclear systems in the real world to the mathematical, and thus, provide the filed for argument, inference, control and decision making in uncertain situation (Momeni, 2006).

\section{The triangular fuzzy number}

One of the most used fuzzy numbers is triangular fuzzy number and is showed in this form $M=(m, a, \beta) .(\mathrm{m}=$ facade, $a=$ distance of facade to the lower bound, $\beta=$ distance of facade to the upper bound)

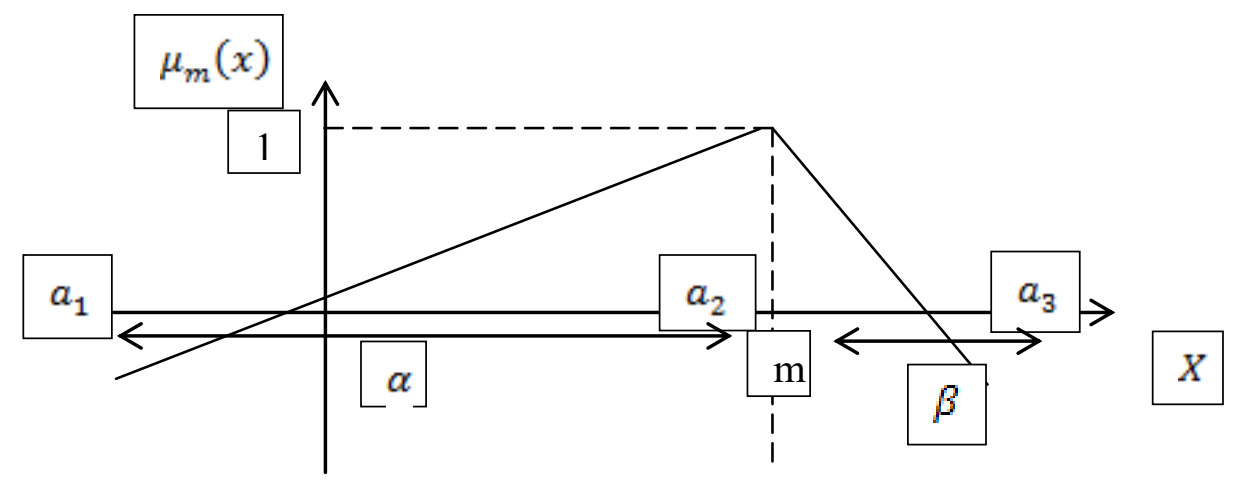

In this study, has used the proposed triangular fuzzy numbers by Lin and $\mathrm{Wu}$. The following table show verbal phrases and their triangular fuzzy numbers. 
Table 2. Verbal phrases and their triangular fuzzy numbers

\begin{tabular}{|c|c|c|}
\hline Five point scale & Verbal phrases & Fuzzy numbers \\
\hline 0 & No influence & $(0,0,0.25)$ \\
\hline 1 & Very low influence & $(0,0.25,0.50)$ \\
\hline 2 & Low influence & $(0.25,0.50,0.75)$ \\
\hline 3 & High influence & $(0.50,0.75,1)$ \\
\hline 4 & Very high influence & $(0.75,1,1)$ \\
\hline
\end{tabular}

\section{METHODOLOGY}

The Fuzzy DEMATEL research method in uncertainty, the analysis procedures are explained as follows:

Step 1: distribution of paired comparisons questionnaire (questionnaire of dematel) inamongst of the company experts. And rate on a scale of 0 to 4 where, 0: no influence, 1: very low influence, 2: low influence, 3: high influence, and 4: very high influence.

After collecting all of the questionnaires following steps done in order to determination of the relationships of components:

Step 2: conversion verbal phrases into triangular fuzzy numbers. Generate a direct relation matrix depicting these relationships. Based on the above components, a matrix $\mathrm{X}$ is generated, which is an $\mathrm{n} \times \mathrm{n}$ matrix. The matrix obtained is the direct relation matrix. In this step, has used the proposed triangular fuzzy numbers by Lin and $\mathrm{Wu}$. And, average of the gathered data in the form of fuzzy from paired comparison matrix, to consider all of the expert opinions, arithmetic mean is taken according to the following formula:

$$
z=\frac{z_{1}+z_{2}+\cdots \ldots \ldots+z_{n}}{n}
$$

Step 3: Fuzzy aggregation normalized matrix. In this step average of paired comparisons matrix in form of fuzzy numbers are normalized by means of the related formulas. Normalize the direct relation matrix $\mathrm{X}$ and form a fuzzy aggregation normalized matrix $\mathrm{E}$. from the fuzzy direct relation matrix $\mathrm{X}$, the fuzzy aggregation normalized matrix $\mathrm{E}$ is obtained as:

$$
\begin{aligned}
E=S & \times X \\
S & =\frac{1}{\left(\operatorname{MAX} 1 \leq \mathrm{j} \leq \mathrm{n} \sum_{\mathrm{j}=1}^{\mathrm{n}} \mathrm{x}_{\mathrm{ij}}\right)} \quad \mathrm{i}, \mathrm{j}=1,2 \ldots \mathrm{n}
\end{aligned}
$$

Step 4: finding the total relation matrix T. After calculating the normalized matrix E, the total relation matrix $\mathrm{T}$ can be achieved by using the formula: (where $\mathrm{I}$ is the identify matrix. Which is also an $\mathrm{n} \times \mathrm{n}$ matrix)

$$
\mathrm{T}=\mathrm{E} \times(\mathrm{I}-\mathrm{E})^{-1}
$$

Step 5: depicting the causal diagram. the sum of rows and columns, within the total relation matrix $\mathrm{T}$ separately denoted as $\mathrm{D}$ and $\mathrm{R}$, using the formulae:

$$
\begin{array}{r}
\mathrm{D}=\left[\sum_{j=1}^{n}\left[t_{i j}\right] n \times 1\right] \\
\mathrm{R}=\left[\sum_{j=1}^{n}\left[t_{i j}\right] 1 \times n\right]
\end{array}
$$


Where $\mathrm{D}$ and $\mathrm{R}$ denote the sum of rows and columns respectively. The causal diagram is found by mapping (D+R; D-R). D+R, obtained by adding $\mathrm{D}$ to $\mathrm{R}$, and gives us the weights and $\mathrm{D}-\mathrm{R}$, obtained by subtracting $\mathrm{D}$ from $\mathrm{R}$, give us relations of components.

Step 6: Defuzzification. In this step, obtained fuzzy numbers (D+R, D-R) from the previous step are defuzzied according to the following formula.

\section{RESULTS}

$$
\mathrm{B}=\frac{\left(a_{1}+a_{3}+2 \times a_{2}\right)}{4}
$$

The following table shows the importance and the relation axis for cause and effect groups all the components of Information Technology in supply chain management:

Table 3. The prominence and relation axis for cause and effect groups(definitive numbers)

\begin{tabular}{|c|c|c|c|c|}
\hline number & $\begin{array}{c}\text { The } \\
\text { symbol }\end{array}$ & Components of IT in SCM & D+R & D-R \\
\hline 1 & C5 & Customer Relationship Management (CRM) & 9.869 & 0.105 \\
\hline 2 & C4 & Supplier Relationship Management (SRM) & 9.812 & 0.138 \\
\hline 3 & C2 & Enterprise Resource Planning (ERP) & 9.682 & 0.209 \\
\hline 4 & C7 & Data Electronic Interchange (DEI) & 9.615 & 0.376 \\
\hline 5 & C3 & Advanced Planning Systems (APS) & 9.610 & 0.499 \\
\hline 6 & C1 & Material Requirement Planning (MRP) & 9.479 & -0.017 \\
\hline 7 & C6 & RFID, GPS, mobile and wireless & 9.081 & 0.060 \\
\hline
\end{tabular}

The DEMATEL analysis produced two categories of results. According to this table, it prioritized the components based on their degree of importance in the decision making context consideration. As explained earlier the importance of components is assessed by $(D+R)$ values. The degree of influence of components is shown in this table 3. The higher value, the more important the components is. Based on $(\mathrm{D}+\mathrm{R})$ values, the importance of seven components con be prioritized as $\mathrm{C} 5>\mathrm{C} 4>\mathrm{C} 2>\mathrm{C} 7>\mathrm{C} 3>\mathrm{C} 1>\mathrm{C} 6$. The result show that the three most important components are: C5: Customer Relationship Management (CRM) (weight: 9.869), C4: Supplier Relationship Management (SRM) (weight: 9.812), and C2: Enterprise Resource Planning (ERP) (weight: 9.682).

Secondly, DEMATEL analysis classified components either as net drivers or net receivers depend on the net influence to the context. If (D-R) is positive, the component is cause component, and (D$\mathrm{R})$ is negative, the component is effect component. The results are shown in table 3 . The results indicate that the two most influential components are: C3: Advanced Planning Systems (APS) ((D$\mathrm{R})=0.499)$, and C7: Data Electronic Interchange $(\mathrm{DEI})((\mathrm{D}-\mathrm{R})=0.376)$. and the impressible component is: C1: Material Requirement Planning (MRP) $((\mathrm{D}-\mathrm{R})=-0.017)$. 


\section{Cause and effects diagram}

The results of the analysis can also be used to develop a causal diagram or cognition map.

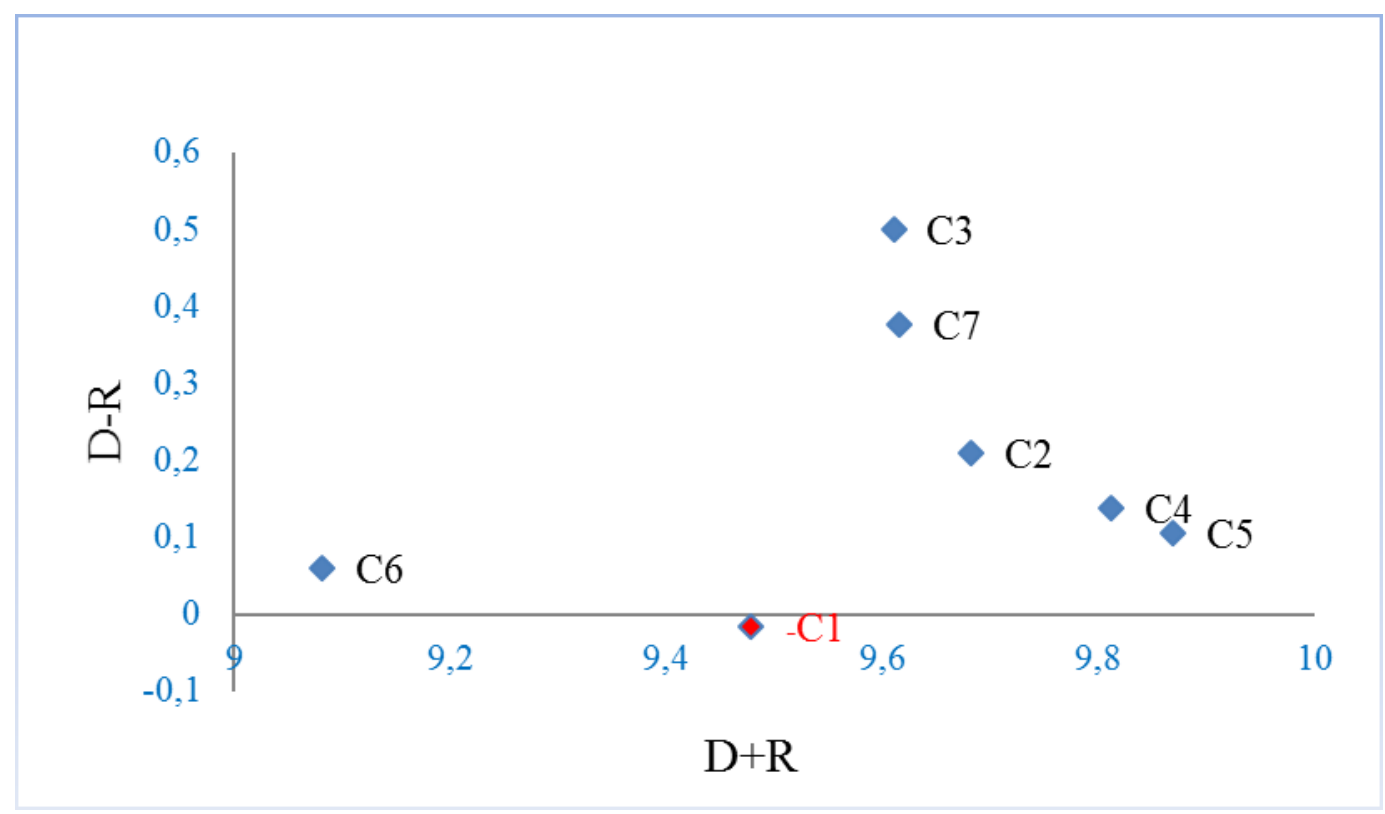

Figure 1.Cause and effects diagram

The cause and effects diagram has been constructed using $(D+R)$ as the $\mathrm{X}$-axis and $(\mathrm{D}-\mathrm{R})$ as the $\mathrm{Y}$ axis. The locations of the components with respect to $\mathrm{X}$ and $\mathrm{Y}$-axis component the degree of importance that the components play and indicate the net effects that they contribute to the context of the study. The figure indicates that among the cause components C3: Advanced Planning Systems (APS) is the main component followed by C7: Data Electronic Interchange (DEI). Advanced Planning Systems (APS) directly impacts on C7: Data Electronic Interchange (DEI), C2: Enterprise Resource Planning (ERP), C4: Supplier Relationship Management (SRM), C5: Customer Relationship Management (CRM).

This study assists us to understand the interrelationships between components more systematically. Understanding of the dynamic nature of the decision-making process through these causal relationships is critical to the implementation strategies of Information Technology in Supply Chain Management.

\section{DISCUSSION AND CONCLUSION}

Overall by comparing the results of this study with the other accomplished studies of related to the subject, in a research was conducted with title of information technology in supply chain management attempts to prove the impact of information technology in supply chain management. The results finds that advanced IT is the cause criteria leading to marketing performance and customer satisfaction (M.L.Tseng, K.J.Wu and T.Nguyen, 2011). Also, this research shows that with investment in components of Information Technology in Supply Chain Management especially, Customer Relationship Management (CRM) can lead to better performance of Supply Chain Management. In another research with title of Information Systems in supply chain integration and management, the literature available on IT in SCM have been classified and then develop a framework for studying the applications of IT in SCM. Based on this review and analysis, recommendations have been made regarding the application of IT in SCM (A.Gunasekaran,E.W.T.Ngai , 2004). In this current study also, proposes precious component for high firm performance which is the IT impact on SCM. In a research with title of the impact of Information Technology on the development of Supply Chain Competitive Advantage, explores the impact of information technology practices on building competitive advantage throughout the supply chain. The empirical findings from a survey of 76 manufacturing firms in Greece confirmed 
companies must exploit IT including enterprise applications such as ERP and CRM, as well as eprocurement and e-commerce, and the crucial role of IT practices and techniques on the establishment of a sustainable competitive advantage based on Supply Chain Management (C.Marinagi, P.Terivellas, D. P. Sakas, 2014). In this study Customer Relationship Management (CRM) was identified as the most important component of information technology in supply chain management and Enterprise Resource Planning (ERP) also as one of the cause component that impacts on the other components.

To successfully adapt the new technology, the managers must pay attention on what kind of technology systems need to be invested and how to aggregate these on their production status. The empirical experimental result will shows out cause and effect components group which gives the guideline for decision-making for managers. Managers should consider what and who to apply information system to get productivity.

\section{References}

[1] Laudon.K.C, Laudon.P.J.(2013) Management Information Systems. Pub.Pearson Education.

[2] Shtub. A. (1999), Enterprise Resource Planning (ERP) .

[3] Orlicky.J. (1974), Material Requiremants Planning .

[4] Hugos. M, ( 2003) ,Essential of Supply Chain Management .

[5] Kaplan. R. S., Norton. D. P, (2004), Strategy Map, Converting Intangible Assets into Tangible Outcomes. Boston, Massachusetts, USA: Harvard Business School Press.

[6] Oblensky,N, (1996), Practical Business .Re_Engineering . Kogan Page ltd . London.

[7] Momeni, M., 1385, the new debates Operations Research, Tehran, Tehran University, School of Management.

[8] Azar, A., Faraji, H., 1381, management science phase, Tehran, publishing community.

[9] Safarzadeh. H, (1392), Supply Chain Management, Tehran, Institute nice book.

[10]Bayazit. O,(2006), use of analytic network process in vender selection decisions. benchmarking, an international journal .

[11]Lee. A.H.I, (2009), A Fuzzy supplier selection model with the consideration of benefits opportunities and risks. Expert systems with application .

[12] Stadtler.H. Kilger. C. (2000), Supply Chain Management and Advanced Planning. Concepts, Models, Software and Case Studies.

[13]Zuckerman.A. (2002), Supply Chain Management.

[14]Tseng. M.L , Wu. K.J, Nguyen. T, ( 2011), Information Technology in Supply Chain Management, International Conference on Asia Pacific Business Innovation \& Technology Management .

[15] Gunasekaran. A, Ngai. E.W.T, (2004), Information Systems in Supply Chain Integration and Management, European Journal of Operational Research .

[16] Marinagi. C, Trivellas. P , Sakas. D.P, (2014), The Impact of Information Technology on the development of Supply Chain Competitive Advantage, Procedia-Social and Behavioral Sciences .

[17]Baruah. S, Raj. S, Shabbiruddin, Ray. A, Chakravorty. S , (2012), Analysis of Influencing Factors for Costs on Substation Siting Based on DEMATEL Method, Procedia Engineering. 
[18] Stewart, R. (2003), IT enhanced project information management in construction path ways to improved performance and strategic copetitiveness automation in construction.

[19] Koch. C, (1996). Flipping the switch. In CIO Magazine, 9(17):43-66.

[20]Wallase, T.F, Kremzar, M.H (2001), Making it happen ( john wiley \& sons Inc).

[21]Gen, M, Cheng, R, Lin, L. (2008), Advanced Planning and Scheduling Models and Optimization Decision Engineering.

[22]Lin, C,L \& Wu, w, (2004), A Fuzzy extension of the DEMATEL method for group decision making. Eroupean journal of operational research.

[23]Kaske,G , ( 2002), my SAP Supplier Relationship Management.

[24]Chopra, S,Mendel, P, (2003), Supply chain management, Strategy, Planning, and Operation, 2nd Ed, Prentice_Hall Inc.

[25]Bort, R, Bielfeld, G,R, (1994), Handbook of EDI. Warrden, Gorham and Lamont, Boston, Massachusetts.

[26]Bloor, M. Wood, F. (2006), Key words in qualitative methods : a vocabulary of research concepts, sage .

[27] Yin, R, K. (2003), Case study research . design and methods (3rd ed) london, sage .

[28] Mokhtarian. M.N. (2011), A note on Developing global managers competencies using the fuzzy DEMETEL method, Expert Systems with Application .

[29] Williamson.E.A, Harrison. D. K, Jordan. M, (2004), Information Systems development within Supply chain management, International Journal of Information Management .

[30]Lotfi, Mukhtar. M,Sahran.S,Taei Zade. A, (2013), Information Sharing in Supply Chain Management. Procedia Technology .

[31] Sumrit. D, Anuntavoranich. P, (2012), Using DEMATEL Method to Analyze the Causal Relations on Technological Innovation Capability Evaluation Factors in Thai Technology Based Firms. International Transaction Journal of Engineering Management, and Applied Sciences and Technologies .

[32] Rahman. S,Qingda, (2013), A Fuzzy Approach to Assess Determinants of Efficient Kerbside Waste Management in an Urban Context.Global Cities Research Institute, RMIT University, Melbourne, Australia.

[33] Gholipour. R, Jandaghi.GH, Rajaei. R, (2012), Contractor Selection in MCDM Context Using Fuzzy AHP. Iranian Journal of Management Studies (IJMS).

[34]Chunling Sun, (2012), Application of RFID Technology for logestics on Internet of Things. AASRI Procedia .

[35] Wu. F , Yeniyurt. S., Kim. D, Cavusgil. S.T, (2006), The impact of information technology on supply chain capabilities and firm performance. Industrial Marketing Management.

[36] Bayraktar. E, Demirbag. M, Koh. S.C.L, Tatoglu. E, Zaim. H, (2009), A Causal analysis of the impact of information systems and supply chain management practices on operational performance. Int. J. Production Economics.

[37] Monczka. RM, Petersen. KJ, Handfield. RB, (1998), Success Factors in Strategic Supplier Alliances: The Buying Company Perspective.

[38]Lotfizadeh. A. (1965), Fuzzy Set, Information and Control, vol. 8, no. 3, pp. 338-53. 
[39] Jafarnejad. A, Ahmadi. A, Maleki. M,(1390), the assessment of the lean manufacturing approach using a combination of techniques ANP and DEMATEL Fuzzy, Journal of Management Studies Industrial eighth year, No. 20, Spring 90, pages 1 to 25.

[40] Moghaddam. N.B, Alavicheh, A, SH,(1388), providing a model of organizational analysis and systematic approach, case study research institution in the field of energy, the Fourth International Conference on Strategic Management Tehran.

[41] Agha Ebrahimi Samani. B, Makuyi. A, Sadr Lahijani. M,(1387), to assess the challenges of Iranian companies in oil and gas projects by DEMATEL, Sharif Journal. 